\title{
From product-oriented flight providers to customer-centric retailers: a dynamic offering framework and implementation guidelines for airlines
}

\author{
Jost Daft ${ }^{1}$. Sascha Albers ${ }^{2,3}$. Sebastian Stabenow ${ }^{2}$
}

Received: 21 December 2020 / Accepted: 27 March 2021 / Published online: 22 June 2021

(c) The Author(s), under exclusive licence to Springer Nature Limited 2021

\begin{abstract}
Industry insiders and analysts see dynamic offering - a highly responsive and customer-centric approach to offer design mirroring the practices of online retailers-as a viable instrument in airlines' quest to regain profitability and maintain relevance in the digitalizing environment. While promising, adopting dynamic offering would also require a major overhaul of airlines' technologies-in-use, as well as their organizational structures and processes in order to overcome the rigidities and limitations from today's pre-defined fare-based offer creation. This paper synthesizes relevant concepts of offer management, outlines airlines' key challenges to offer management adoption and suggests guidelines for airlines' transition from pure flight providers to 'airline retailers' along six imperatives.
\end{abstract}

Keywords Continuous pricing $\cdot$ Dynamic bundling $\cdot$ Dynamic assortment optimization $\cdot$ Airline digitalization

\section{Introduction}

Online retail has been thriving: US sales nearly doubled between 2013 and 2019 to US $\$ 595$ billion (U.S. Department of Commerce 2020). A considerable portion of the growth in online retail can be related to the increasing deployment of dynamic pricing (Angwin and Mattioli 2012), or product personalization practices (Hannak et al. 2014). Online retailers are responsive to real-time customer and contextual information, proactively displaying product recommendations and personalizing products and prices to create more relevant service offers. This contrasts to airlines, which are

Jost Daft

jost.daft@dlh.de

Sascha Albers

sascha.albers@uantwerpen.be

Sebastian Stabenow

sebastian.stabenow@uantwerpen.be

1 Deutsche Lufthansa AG, Venloer Str. 151-153, 50672 Cologne, Germany

2 Dept. of Management, University of Antwerp, Prinsstraat 13, 2000 Antwerpen, Belgium

3 Antwerp Management School, Boogkeers 5, 2000 Antwerpen, Belgium still bound to static product-centric offerings based on preinternet technology such as fare tables. Thus, "becoming the Amazon of air travel" (Jenner 2017)—that is, evolving from flight providers to retailers of airline services (Hoyles 2015) to counter the commoditization and homogenization of airline offers (Tarry 2010)—could be a promising option for airlines.

Two particular recent developments have encouraged airlines confidence to mimic the practices of retailers. ${ }^{1}$ First, advancements in digital, algorithm-based business processes have enabled real-time and cost-efficient data analytics, such as customer willingness-to-pay (WTP) estimations (Chen et al. 2016a). Second, the new industry data transmission standard, facilitated by IATA's New Distribution Capability (NDC) initiative, enables differentiated and transparent product search and response between customers, airlines, and distribution partners (Hoyles 2015). Airlines that embrace these new developments are able to overcome eminent technical and structural constraints from legacy systems and catch up to the firms that lead in terms of innovative service/product marketing and distribution in an increasingly digitalized travel industry.

However, few scholars have discussed the adaptations that are necessary to successfully build customer-centric retailing

${ }^{1}$ For simplicity, we use the term "retailer" to denote online retailers throughout this study. 
capabilities for the airline industry (e.g., Vinod 2007). Those that have come closest have analyzed airlines' offer differentiation, particularly differential pricing (Bilotkach 2010) or customer price elasticities (Granados et al. 2012) across distribution channels. Among airline practitioners, reference to airline retailing is widespread and frequent (e.g., Ferguson 2014; Jenner 2017) but remains conceptually vague and ambiguous regarding airline retailing characteristics and requirements. The gap between practical enthusiasm and scholarly hesitation breeds frustration, impedes construct clarity, and limits the development of conceptually sound bases for well-informed and balanced management decisions.

The present paper addresses these challenges: It consolidates the dispersed contributions surrounding airline retailing, develops an organizing framework of customer-centric airline retailing, and provides a practical guide along six imperatives that can help airline managers on their way to the future retail offering world. The paper, therefore, facilitates further studies on dedicated airline retailing practices and conditions, and supports managers in their decisions on a potential modernization of airline offering capabilities.

We proceed as follows: we first map the industry's "retailing status quo" by assessing current offer creation practices rooted in product bundling and revenue management (RM). We then synthesize the current research on offer creation, revenue management, and customization to develop the organizing framework for customer-centric retailing. Finally, the managerial guidelines for implementing customer-centric retailing are introduced, before we conclude.

\section{The status quo of airline retailing}

\section{The long breath of the past}

Airlines pioneered e-commerce back in the 1970s, long before the rise of the internet (e.g., Boyd 2007). Distributing their offers via computer reservation systems (CRS), airlines were able to efficiently sell their highly perishable service to travel agents around the world in a heavily automated and efficient manner.

However, their reliance on CRS conserved airlines' product-oriented (rather than customer-centric) offering mode. Airlines' product orientation is reflected in the way offers are created and presented to the customer: offers are pre-defined and filed in fully standardized description tables without any opportunity to customize them. Fare files use a rigid frame of globally standardized parameters that precisely determine, bit by bit, how an offer with its conditions should be constructed by the travel agent. Any new forms of offers would require an adjustment of the global filing standard beforehand. Once published, a defined offer remains in the market for months or even years without major adjustments. Changing customer needs and behavior can hardly be matched with this static offer creation. These static offers are displayed in normalized views that are sorted purely by flight time or price without any chance to provide differentiating product features compared to competitors' offers. In contrast, retailers use a plethora of parameters, such as previously observed customer preferences and product recommendations, to sort and rank the offer display individually for each customer beyond pure price sorting.

Normalized offering was sufficient in times of regulated markets. When de-regulation in the airline industry opened the market to fierce competition, the race for customer centricity started. Yet, airlines still stick to the same limited legacy processes to create, distribute, and sell their offers despite their enlarged product portfolio that now also includes a wide set of bundled and unbundled à la carte ancillary services, in addition to their all-inclusive transportation fare offers.

But why do airlines continue to struggle with the provision of differentiated service offers and the merchandise of ancillary services? First, global distribution system (GDS)based distribution channels, through which approximately $60 \%$ of airline revenues are generated (Tretheway and Markhvida 2014), encourage price-based fare comparisons (Granados et al. 2012), and thereby impede offer differentiation. Second, airline websites and mobile applications, as the second-most important distribution channels, enable control over product presentation (Koo et al. 2011), direct customer interaction, "do-it-yourself" service customization, and customer relationship management (Budd and Vorley 2013) but face inherent business and technical constraints. Business constraints arise from long-standing distribution contracts with GDS, which oblige airlines to make fares sold on their website also available in GDS-based distribution channels (McDonald 2015), thus, inherently constraining the potential for differentiated products on airline websites. Technical restraints come from insufficient capabilities of airlines' IT systems to enable more progressive distribution practices and flexible data exchange in the highly connected industry (Flottau et al. 2015). This fact is illustrated in the long path of the industry to eventually replace outdated paper tickets with electronic tickets. Even though the first electronic ticket was issued as early as 1994, it was not until mid-2008 that it fully transcended the industry (IATA 2008). The airline industry, once an e-commerce pioneer, is currently trailing behind new e-commerce retailers (see Fig. 1).

\section{Current airline industry practices}

E-commerce firms, which range from online retailers like Amazon and Alibaba to digital service providers such as Netflix or Uber, have been remarkably successful at hyper 


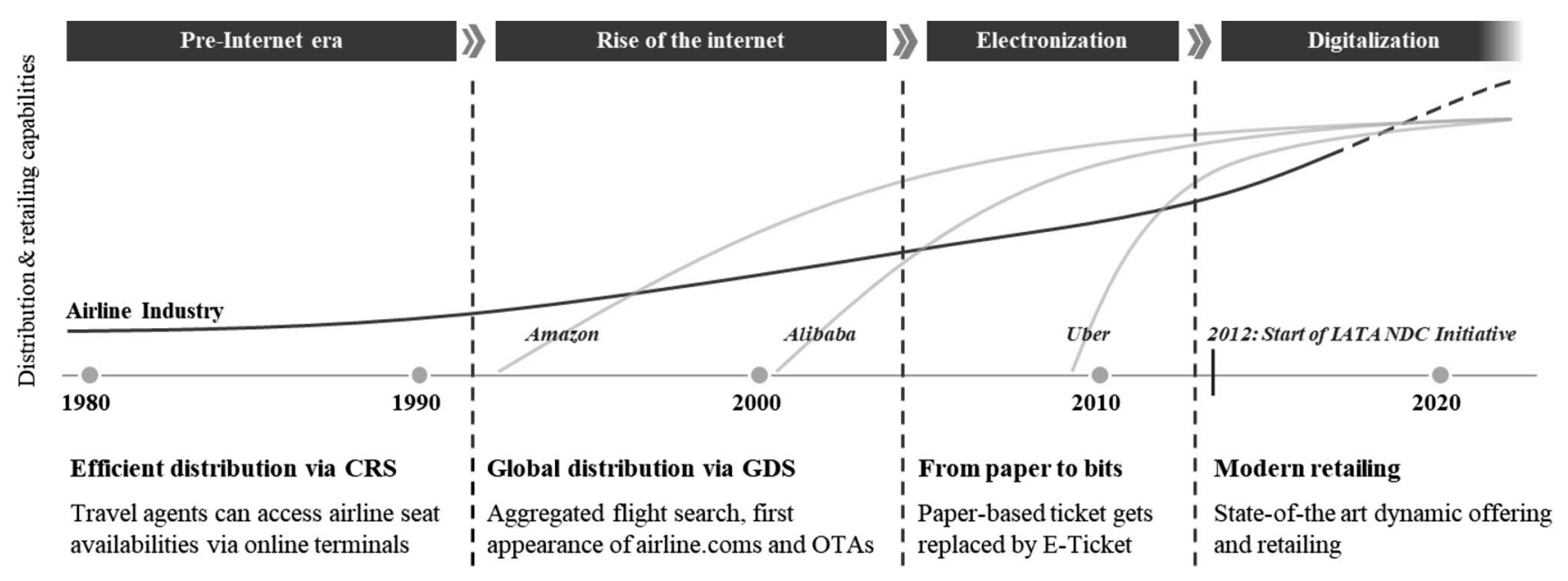

Fig. 1 Development of airline distribution and retailing capabilities

data-driven product personalization and cross-selling (Ferguson 2014). Beyond seamless multi-channel management and sophisticated online store functionalities (such as interactive product catalogs), the success of e-commerce firms is predominantly driven by state-of-the-art offer creation practices that are directly linked to customer needs. Amazon and other e-commerce firms have continued to expand and refine classic revenue management techniques by personalizing products, upselling recommendations, and offering prices for each arriving customer based on massive transactional customer data (e.g., Golrezaei et al. 2014). Following the success of these e-commerce firms, airlines-like many other players-look at their example to define the target characteristics of their future service offers.

Airline managers and scholars are increasingly referring to an airline's offer (in contrast to the legacy fare) to emphasize a growing focus on the integrated sale of transportation service (that is, the seat) and ancillary services, rather than single fares alone (Fiig et al. 2015; Hoyles 2015; Wittmann and Belobaba 2016). Airline retailing, in turn, is used to summarize the characteristics of airline offers, such as differentiation, time-to-market, and personalization (IATA's NDC strategy: Hoyles 2015), value-added bundles, à la carte services, and personalized packs (Amadeus IT Group 2014), or real-time customer request evaluation, product selection, and personalization (Westermann 2013).

In recent years, the prominence of airline retailing has constantly increased. In addition to airlines, major industry initiatives (such as IATA NDC), most airline IT providers, and consultancies have subscribed to the promise of data-driven customer centricity as the key success driver. Accordingly, a sizeable amount of dedicated airline retailing white papers, expert conferences, and events have emerged (for example, "Where is the Value in Airline Retailing" by
McKinsey, 2019, "Airline Digital Retailing Survey,” 2019 by Diggintravel, IATA's Airline Industry Retailing Symposium, T2RL's PSS Conference, and AI's Ancillary Merchandising Conference), underlining the growing demand for airline industry players. However, airlines' current practices are still mostly based on classical product bundling and revenue management techniques.

\section{Product bundling}

Airlines' decisions regarding which services/products to offer are largely rooted in product bundling strategies. Theory distinguishes between the strategies of pure bundling, unbundling, and mixed bundling (Stremersch and Tellis 2002), which translate, respectively, to unbreakable fares consisting of flight and ancillary services, the à la carte provision of ancillary services, and a combination thereof. Flight offers have traditionally comprised unbreakable flight/ service combinations with typical services including checkin facilities, seat assignment, or in-flight meals. Over the last few years, service unbundling-such as charging fees for advanced seat reservation, on-board food and drinks (O'Connell and Warnock-Smith 2013), or checked baggage (Scotti et al. 2016) - has gained popularity among airlines. Combined with the expansion of ancillary service portfolios, these practices leave customers with considerable freedom to define the content of an offer (customer-driven customization). The resulting similarity in airline fares, recently pushed to the extreme with the introduction of flight-only fares (Boynton 2012; Fageda et al. 2015), has resulted in price-driven offer differentiation and competition for fares aimed at price-sensitive customers. Many airlines have introduced pre-defined product bundles, referred to as branded fares, to establish differentiable products, drive customer 
segmentation, and proactively trigger upsell (Vinod and Moore 2009) in market segments with higher customer WTP. From their labeling, branded fares are meant to be recognizable and support an airlines' brand (Vinod and Moore 2009), which is one reason why content is inherently static over time and across customers. Furthermore, the industrywide adoption of unbundling and static bundling practices has raised doubts about whether these practices are suitable to drive offer differentiation.

\section{Revenue management}

Besides bundling, revenue management lies at the core of current offer creation processes. While theory distinguishes between price-based (such as price adjustments) and quantity-based (such as assortment optimization) RM (van Ryzin and Talluri 2005), both types essentially result in changes in fare prices as displayed to customers.

There is limited empirical evidence about whether changes in market prices relate to actual price updates or capacity control mechanisms. On one hand, airlines engage in dynamic pricing, thereby manually updating prices over the sales horizon (van Ryzin and Talluri 2005). Airlines' practices of aligning their own prices to those of competitors (Clark and Vincent 2012) represent a typical example of dynamic pricing. However, updating prices is a resourceintensive and time-consuming process, particularly if fares need to be filed ${ }^{2}$ for distribution via intermediary distribution partners (Vinod 2010). Consequently, despite some early moves (for example, Lufthansa Group started market roll-out of continuous pricing in 2020), airlines appear to be engaging in frequent but not real-time updates of fare prices.

On the other hand, airlines apply capacity control mechanisms, such as assortment optimization, to determine the (set of) fare(s) displayed to customers that will maximize flight revenue. By offering different fares with different prices for the same product to customers based on trip characteristics, such as minimum length of stay, airlines price discriminate across customers to account for (assumed) differences in customers' WTP and to reduce the risk of customer down sell (Vinod 2010). Furthermore, airlines update the fares available for sale based on real-time inventory information. As fares are linked to booking classes, capacity is shifted to classes with higher fare prices as more seats are sold (van Ryzin and Talluri 2005). Both highlighted assortment

\footnotetext{
2 Airlines file fares with and submit fare changes (in price, for example) to fare aggregators (such as ATPCO) as a means of making available airline fares to a range of distribution partners. Aggregators consolidate and share airline fares a few times per day with participating global distribution systems that are accessed by travel agencies (Vinod 2010).
}

optimization approaches result in airlines using real-time information on seat inventory or customers' journey characteristics to dynamically map customers to pre-defined fares.

Overall, retailing-specific practices seem to be still scarce across the industry. Information used to update fare prices and assortments displayed is limited to real-time, generic offer requests and inventory information and frequent reviews of competitor fares but does not include customer and additional context data. Offer customization is predominantly left to customers who choose to enrich flight-only or static, homogeneous, bundled offers with ancillary services. Also, new forms of pricing such as travel passes and subscription models that are well known from other industries are rarely adopted in the airline industry (see also Jainchill and Silk 2019; Franko 2021). While for the subscription model, various challenges to match the pre-paid fixed price with existing inventory-based RM approaches arise, it promises new revenue streams and increases customer loyalty. In particular, for ancillary services, there have already been attempts by some airlines to introduce subscription schemas. Innovative forms of pricing including subscription models could further drive a customer-centric retailing. Yet, customer centricity has relied on price-based segmentation across airlines and customer segments.

\section{The play ground: a framework for customer-centric retailing}

Mounting attention from airline managers, which has hardly been reflected in airlines' processes and procedures so far, might be seen as an indicator of major uncertainties surrounding customer-centric retailing in practice. A lack of specification of potential airline retailing approaches and their varying requirements seem to impede the industry's progress in this area. In this section, we suggest an organizing framework that brings together the key concepts and their relations from the current discourse on airline retailing and offer management (see Fig. 2). By specifying the most frequently used concepts (such as "customer centricity" and "dynamic offering") in this domain and organizing them in our framework, we aim to provide a platform for both academia and practice to further and jointly advance understanding, development, and diffusion of the retailing concept in the airline industry.

The business goal is at the top of the framework: increasing customer satisfaction by providing more relevant offers while, at the same time, improving the company's profitability through exploiting the full willingness to pay. The offer is at the center of the framework. It refers to a set of priced and conditioned products (that is, offer items) that is ready to be purchased by the customer. Following the recently established IATA nomenclature, in the context of the airline 
Business goal: Build a customer-centric retailing to increase customer satisfaction while improving company's profitability

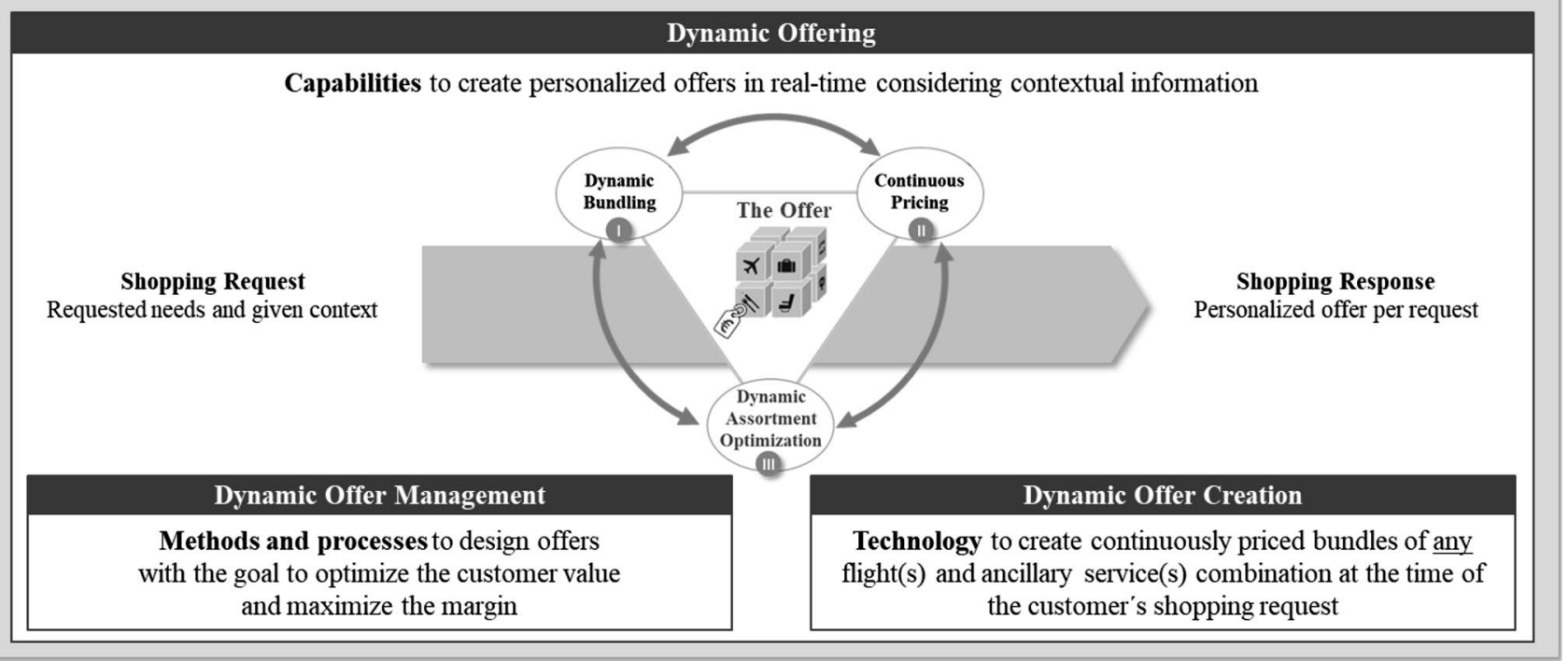

Fig. 2 An organizing framework for customer-centric retailing

industry, offer items can be flight itineraries (that is, the passenger transportation service) or any other ancillary service that can be flight related (such as special in-flight meals) or even non-flight related (for example, chauffeur service). Offer items represent the atomic pieces of a final offer. They can be sold to customers as standalone entities with own price tags and conditions or be put together into bundles as unbreakable entities, with one price for the full set of items included in one offer. A final offer to the customer carries all necessary information, such as the consumer price (including fee and tax breakdown, if applicable) and the conditions of consumption (such as refund rules) for being transferable straight into an order (that is, a binding contract).

Dynamic bundling, continuous pricing, and dynamic assortment optimization are the core components of processing individual customer shopping requests in real time using contextual information; overall, we refer to this process as dynamic offering. Studies in this domain have particularly emphasized the revenue benefits associated with price (Aydin and Ziya 2009) and assortment (Golrezaei et al. 2014) personalization to individual customers.

\section{Dynamic bundling}

Reaching the business goal of increased customer satisfaction (apart from the quality of the sold product itself) is driven by the capability to personalization-based offer differentiation that enables firms to move beyond segment-specific averaging of customers' preferences and WTP towards tailoring of offers to individual customer needs and preferences. Each customer has his or her own perception and preferences for a particular desired product, which-along with the customers' personality and attitude-are strongly determined by the context of the shopping situation. The same individual customer might have significantly different preferences, whether he or she is shopping for a weekend trip with friends using an online metasearch engine or for a family vacation using a mobile device. In the past, those preferences were mostly neglected leaving the customer with only partly fitting offers and average satisfaction. In turn, being able to recognize the particular shopping context (that is, use of real-time observable information) and build differentiated offers tailored to the individual customer needs that include supplementary services/products along with the flight, will improve the customer satisfaction and proactively drive cross- and upsell. Such firm-driven data-based upsell recommendations can trigger customers' purchase of more feature-rich products over customer-driven productby-product enrichment (Hildebrand et al. 2014). The entire activity of reading the real-time shopping request information, enriching it with additional context information, and deciding about the items and their way to be offered (combination of standalone and/or bundles) is the first step towards coming up with the final offer. We label this as dynamic bundling.

\section{Continuous pricing}

Closely linked to the decision of what to offer to the customer is the question of the price for each offer. In analogy to the bundling decision, the pricing should happen real time; that is, at the second that the customer initiates 
the shopping request and based on the available contextual and transactional data. Using currently emerging new datadriven pricing solutions, optimizing the pricing of an offer will bring significant margin improvements. Regardless of whether airlines focus on value-based or competitionbased pricing strategies, real-time observable information can enhance pricing based on more accurate estimations of customers' WTP or improved competitive position, such as faster competitor price matching (Fiig et al. 2016). Considering the aim of enabling continuous (instead of discrete) price curves, the pricing step is referred to as continuous pricing. By avoiding the price jumps that came along with legacy fare-filing-based pricing and its limited price points, the customer becomes more central to the pricing decision: customer preferences and actual WTP determine the price eventually offered by the airline rather than technical limitations.

\section{Dynamic assortment optimization}

Once a set of suitable offers for a particular shopping request has been created, dedicated offers still need to be displayed to the customer. Assuming that bundling and pricing application will result in not only one signal, but several offers that equally match the estimated customer preferences, the airline has made a decision about which offer(s) to actually present to the customer. This decision domain is well known, especially from classical retailers that manage the physical placement of their products with increasingly data-driven assortment optimization tools. Assuming that the display space for shopping content is limited to a maximum of five dedicated offers, a thorough calculation of conversion probabilities is required, considering multiple contextual factors (including the channel-specific shelf characteristics) and incorporating customer behavior (see, for example, Adaval and Monroe 2002). Considering the real-time nature of this placement decision for each individual shopping request, it is denoted as dynamic assortment optimization.

Each of the three components has sparked a growing base of research yet warrants additional efforts along methodological, processual, and technological fronts.

Methodologically, key to the development of a new dynamic offering capability that integrates bundling, pricing, and assortment optimization is a suitable and solid foundation. While today's methods and algorithms for offer optimization are deeply rooted in the RM domain (with strong links to operations research) and mostly focus on singular optimization (that is, either price or content), an integrated method requires a broader linkage to adjacent fields in the behavioral sciences and data analytics to create (more) efficient optimization methods that enable a truly customer-centric offering fueled by an ever-increasing product portfolio.
Closely linked to the development of new and integrated offer, optimization methods are the quest for a suitable offering process. The effectiveness of a highly sophisticated algorithm is strongly determined by its embedding into suitable processes that ensures required data provision and flows, keeps users in a proper information and steering loop, and supports a meaningful allocation of roles and responsibilities within an increasingly cross-functional work mode. Such a process design also includes the formation of an organizational setup that supports the establishment and continuous improvement of new data-driven optimization methods via an effective formal structure and proper knowledge management. Methods and processes with the goal of maximizing the customer and firm value (that is, the margin) can be jointly considered as dynamic offer management.

To eventually build dynamic offering capabilities, however, dynamic offer management alone is not sufficient. Rather, proper technology such as real-time pricing engines, product recommenders, user interfaces, and data processors that can run the optimization methods according to the defined processes are required. Therefore, the success of building dynamic offering capabilities is equally dependent on the right technology: Technology allows the transformation of all relevant inputs from the dynamic offer management into the actual creation of shopping responses with ready-to-purchase offers for each individual shopping request. The entire technology stack, including the optimization applications to create continuously priced bundles at the time of the customer's shopping request, can be subsumed under dynamic offer creation.

With the central dynamic offer elements and their relation on the table, the question that remains for airlines is how to best move towards such future retailing. In the next section, we develop a pragmatic guideline for airlines on how to navigate an eventual dynamic offering adoption, moving them towards airline retailing.

\section{A guideline for airlines on how to move towards retailing}

Airline retailing is widely seen as a promising approach for airlines. Based on a broad screening of current airline approaches to implement dynamic offering capabilities between 2017 to 2020, including various industry initiatives (such as the IATA Dynamic Offer Forum), solution providers, and consultancies, we suggest six imperatives on the path to customer-centric airline retailing (see Fig. 3).

\section{Provide robust statistical and optimization models}

To overcome today's frequent use of contractually defined fare conditions and limited number of booking class-based 


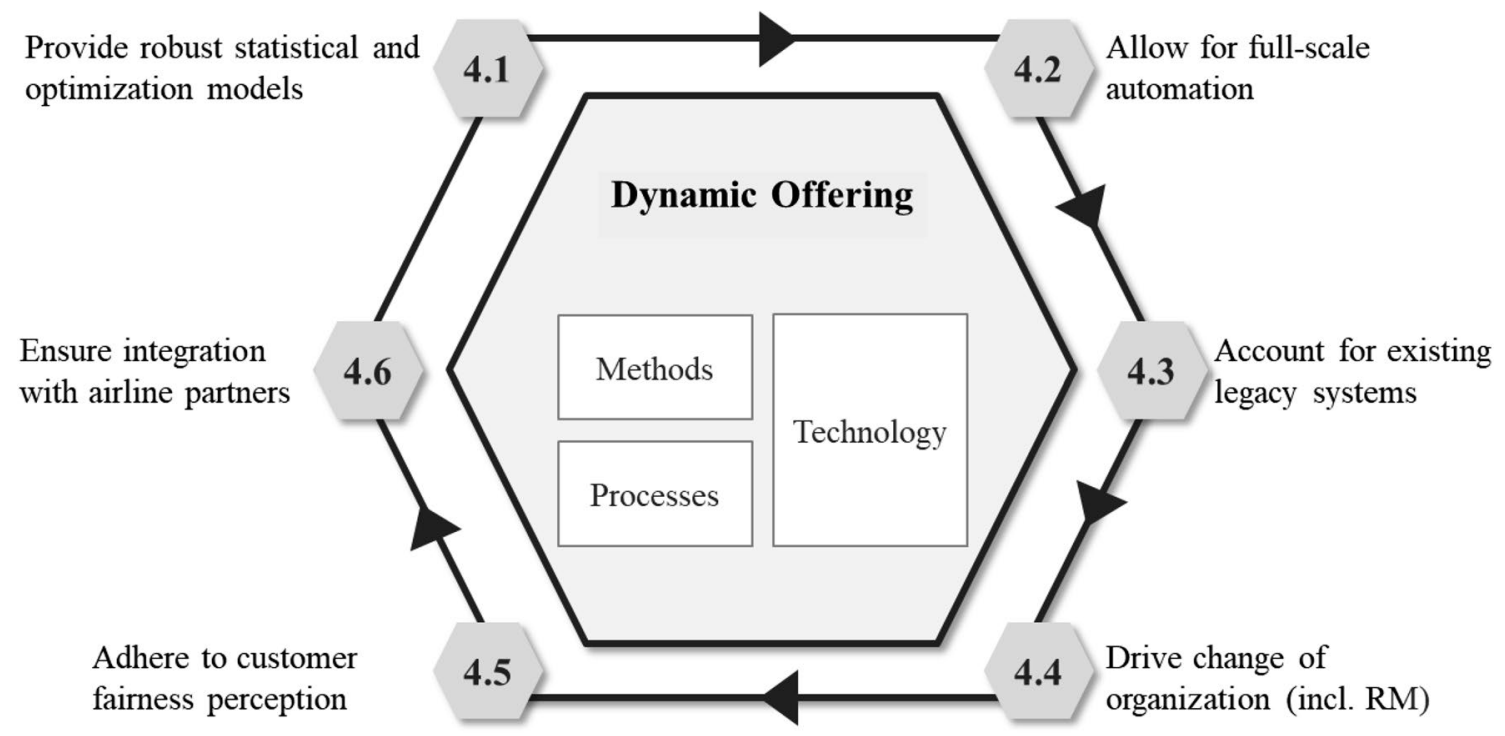

Fig. 3 Six imperatives in the development of dynamic offering ( adopted from Daft and Viehmann 2019)

price points as two prevailing obstacles in RM (Chen et al. 2016b; Westermann 2013), a real-time calculation based on multiple contextual input factors is key. However, considering the amount of data, parameters, and methods that could feed into an optimization model, some guiding principles should be used to eventually ensure robustness of the developed statistical and optimization models. Robust estimations can particularly help to build confidence of users and management in the quantitative modeling approach during early stages of the development.

Following earlier work on the advancement of standard RM methods, demand forecasting and price optimization should be disentangled (Rauch et al. 2018). While capacity control can be realized via bid prices, price optimization could be built on WTP estimations. While price elasticity estimation methods for single offer items are well advanced today, the estimation for multiple offers with their inherent relationship is still in its infancy. To build the required cross-price elasticities, an experimental model approach can support the stepwise enhancement of as suitable method. In the same vein of stepwise development, model design should allow for regular parameter and dimension expansion with regard to segmentation and elasticity estimation. While it is preferable to eventually reach an integrated model for content (that is, the offer items and their way of combination/bundling) and price, a dual approach could initially support a smooth transition from semi-automated offer creation to fully automated AI-driven offer creation by optimizing the price based on existing algorithms and using pre-defined syntactical rules for the offer item provision. Using pre-defined rules also helps to actively keep the users in the steering loop instead of handing the entire decision to automated systems right from the beginning (see "Drive change of organization (including RM)" section).

\section{Allow for full-scale automation}

The flexibility to create an offer as a bundled combination of various service items and the growth of available contextual data for the real-time calculation of optimal offers is a key enabler for the success of customer-centric retailing. However, it comes with a new risk that needs to be managed carefully: an increase in complexity. With a product portfolio of only 15 dedicated items (and, for simplification, a limitation of the shopping response to 15 services, and neglecting association with a dedicated flight itinerary), up to $77,558,760$ combinations can be built. Even the most proficient user cannot manage this amount of options manually, nor can a customer understand and consume this avalanche of potential offers (see also "Adhere to customer fairness perception" section). Therefore, the development of the underlying robust optimization methods (see "Provide robust statistical and optimization models" section) needs to consider full automation right from the start. This includes the proper design of models and their parameterization, regular model training approach, as well as proposed applications during real-time offer calculation. As part of the design, automated data provision (including data preparation) also needs to be considered. Data feeds that are required for model application and/or training benefit from being available without the need for manual interception (see "Account for existing legacy systems" section). With the user in the steering loop, a major component in the automation of the offer optimization is a suitable user interface that allows for an efficient 
handling of system configurations and influences. The user interface design needs to consider the amount of combinations and their association to a sufficiently granular market level to allow for meaningful rule settings.

Missing a suitable automation concept during the design phase of the optimization models will significantly limit the usability of the model, as continuous growth of the product portfolio that needs to be considered in the optimization is likely. Considering the amount of combinations (strongly driven by the association with the flight itinerary), the success of a customer-centric airline retailing depends heavily on full-scale automation.

\section{Account for existing legacy systems}

The automated information processing of IT systems has laid the foundation for a global airline distribution but has led to strong coupling of distribution and offer creation capabilities and a substantial involvement of intermediaries (Tretheway and Markhvida 2014). The corresponding airlines' and GDS's legacy IT systems, which were mostly built in the pre-internet era, show inherent shortcomings in terms of supporting more dynamic price (Isler and D'Souza 2009) or content updates. While next-generation IT systems will speed up processes of offer customization, personalization, and new forms of pricing such as subscription models, the existing IT landscape needs to be considered as a decisive pillar in the design of a migration plan because a build-up of new IT solutions from scratch, as seen in the booming retail industry, is hardly possible in the highly connected airline industry.

Despite its expected challenges to drive IT innovation while still maintaining the legacy systems (most importantly the passenger service systems) that are at the heart of any passenger airline operations, some principles should guide the change of the offer creation-enabling IT. While existing systems were built as monolithic blocks that bundled several functions (for example, offer creation, offer distribution, passenger handling), new solutions would benefit from a modular design. To ensure connectivity of various modules, the use of APIs and open industry standards should be championed. By changing from-mostly proprietarylegacy standards (that is, EDIFACT) to open standards based on technology advancements (such as machine as well as human-readable XML schemas) a new eco-system with existing and new solution providers from within and external to the airline industry can be supported. These will support the inflow of innovations and shorten the solution life cycles to allow for continuous improvement and adjustment to evolving retailing methods and processes. Therefore, the IATA NDC and ONE Order initiatives are key drivers of the current change of the IT eco-system.

\section{Drive change of organization (including RM)}

In addition to tangible resources (such as IT systems), intangible resources (such as organizational processes, culture, and employee capabilities) are important for supporting a company's competitive advantage (Grant 2010). Considering the fundamental change from fare-filing-based product orientation to customer-centric airline retailing, aligning organizational processes, culture, and employee capabilities to airlines' targeted retailing approaches is inevitable. It has already been emphasized that current airline processes need to be adjusted in order to support more dynamic price updates (Fiig et al. 2016). The creation of customer-centric offers spans internal product, pricing, and distribution departments, external partners and marketing, sales, distribution, and service delivery processes. The need for alignment across these parties rises as offer complexity (that is, personalization-based differentiation) increases. Consequently, pursuance of airline retailing characteristics requires an adjusted organizational setup of processes, culture, and employee capabilities in several areas. This notion is particularly relevant considering airlines' long-standing emphasis on revenue management and legacy distribution practices, which may result in structural inertia towards retailing approaches and new offering types and pricing forms (e.g., subscriptions).

Key to the organizational change is the transformation from dedicated control for each offer (that is, fare) to generic frameworks that describe the parameter range for the design and steering of offers. Such frameworks will allow for shared responsibilities and joint goals among various processes, in contrast to previously individuals goals per process domain. Instead of controlling each individual price point in today's RM world, frames will define the range within distributed users, and the automated systems can set offer rules and parameters more regularly (or even in real-time). Frameworks also support the definition and application of multiplex hierarchical offer creation rules that are key for robust statistical optimization. As frameworks will become the DNA for the offering organization, they will also determine the future organizational design and process flows that need to reflect the cross-functional responsivity and the everincreasing responsiveness. To ensure a smooth transition into the new setup, involvement of the users right from the start of the transformation is required. Design of methods and solutions needs to go hand in hand with the process design to define the proper level of user embedding into the information and steering loop of the automated solutions. This will ensure the commitment of the users to actively shape the paths towards customer-centric retailing. To support the user commitment, a clear field of actions needs to be defined for empowering the people from various fields of expertise (from RM but also marketing, sales, product, etc.). 
Investing in digital retailing competences and (re-) training of competences in data sciences are key, as are new forms of working, to build-up a customer-centric mindset in the organization.

\section{Adhere to customer fairness perception}

In today's digital retailing world, customers are well informed about available offers in the market, which necessitates careful management of the newly gained flexibility to create optimized dynamic offers. In addition, the adoption of airline retailing characteristics and approaches is subject to international air transport regulation as well as idiosyncratic country legislation on data privacy and consumer protection. For example, data privacy or non-discrimination based on gender, race, and religion are handled differently across countries and will set boundaries regarding, for example, the use of customer data in offer personalization. To date, offer management practices beyond pricing have largely been exempted from regulation, but the governments of countries including the United States have announced that they will closely monitor the need for enhanced consumer protection in light of airline retailing practices (Walker 2012). In consequence, constraints to pursue certain airline retailing characteristics may arise from the scope of airlines' crossborder operations and exposure to an individual country's regulations.

The ability of airlines to create customer-relevant offers and customers' attitude towards these offers defines prerequisites for achieving full customer centricity. At its core, customer-centric offer creation relies heavily on the ability of firms to (a) correctly identify customer preferences and (b) respond to customers' needs, drawing upon a relevant product portfolio, with the former being heavily dependent on customers' awareness of and ability to express their preferences and their involvement with the product (Franke et al. 2009), as well as their willingness to share personal data.

Customers' attitudes towards retail-oriented offers are key for the feasibility of retailing approaches. Customers' perceptions of offer unfairness along with perceptions of offer complexity can lead to unfavorable customer behavior (Chung and Petrick 2012; Homburg et al. 2014). The complexity and dynamism of RM practices has already raised concerns among customers about the perceived fairness of airline fares (Aslani et al. 2014). Therefore, key principles need to be defined that ensure customer fairness perceptions are not violated. It is essential to consider design systeminherent boundaries that control the automated offer creation to avoid unfavorable offers (for example, sky-rocketing prices in crises, as happened during the Fukushima disaster when demand for travel out of Japan automatically drove the system). As contextual and customer data are key for any personalization, it is also of the utmost importance to prove to the customer that their shared data are kept safely and used only for their benefit. Accordingly, customers who identify themselves (for example, via their frequent flier number) will always be rewarded with better offers instead of being penalized with higher prices. Eventually, transparent communication (Chung and Petrick 2012) will also help drive customers' attitudes towards offer personalization.

\section{Ensure integration with airline partners}

Due to heavy dependence on other airlines to allow for truly global network coverage, any move towards customer-centric retailing will also be determined by an airlines' ability to connect their new dynamic offer creation to partner airlines. This includes the integration of various IT solutions by using not only new open industry standards (see also "Account for existing legacy systems" section) but also the offer definition process. Today's joint airline offer creation is based on interline and codeshare procedures and follows a delegation approach, where a partner's airline will eventually modify the provided fare and availability components for the final offer. The future interline concept could rely on the notion that each participating airline will provide sealed ready-topurchase offer items via standardized interfaces, in contrast to today's setup, where the offer itself must be highly standardized (that is, un-differentiated) while being unprotected against probably unintended modifications. A basis for the targeted customer-centric response of offer components within an interline offer will be the proper sharing of contextual data where possible within the legislative boundaries (see also "Adhere to customer fairness perception" section).

Critical to the transition paths is the decoupling of the own and the partner's offer creation solutions. By using a minimum defined set of generic exchange standards, it will be possible to integrate different airline offer creation systems independent from their underlying logic (that is, booking-class-based fare files vs. class-less dynamic offer creation). Thus, airlines of different development tracks still can maintain a joint offer creation, which is critical for each's individual success.

\section{Outlook and conclusion}

We suggest an organizing framework for customer-centric retailing and provide a guideline that can help airline managers maneuver through various decision items on their organization's individual way towards dynamic offering adoption. Our novel approach is an initial step towards organizing the airline retailing conceptual space, which has advanced rapidly in recent years. As such, our approach also raises ample opportunities for refinement and further investigation. 
For example, we have mostly abstracted from a finegrained differentiation of different airline contexts. However, the individual firm's situation (such as the business model) will have an impact on the relevance and strategic priority in attending to the six imperatives. For example, the need to integrate airline partners might differ heavily between a full-service carrier and a low-cost carrier (Daft and Albers 2013; Albers et al. 2020).

Also, we rely on a conceptual exposition and anecdotal evidence for the development of our retailing implementation guideline. Hitherto observable airline retailing practices in the industry are still in their infancy, preventing a broader empirical assessment. As soon as customer-centric retailing has diffused more widely into the industry, researchers and analysts can engage in more detailed quantitative success factor analyses. Interviews with airline managers and stakeholders will likely unearth additional prerequisites that are key to future research and firms' adoption of airline retailing.

We have focused on management measures that can support the implementation of customer-centric retailing. However, progress in the development of quantitative methods (see "Provide robust statistical and optimization models" section) will be paramount. In line with new efforts made on the dynamic pricing of ancillaries (e.g., Odegaard and Wilson 2016) and the dynamic generation of offers (e.g., Wang 2020), further research needs to focus on airlines' operationalization of dynamic bundling and pricing methods to present suitable models that advance today's RM approaches.

The highlighted benefits of airline retailing appear to justify airlines' emphasis on retail-oriented service offers to counteract service commoditization and homogenization in a margin-weak industry. Its relevance might even be propelled in the aftermath of the COVID-19 pandemic that is currently wreaking havoc among airlines and promises to massively impact the post-pandemic competitive landscape (e.g., Albers and Rundshagen 2020). While the frequent comparison to Amazon serves as a catchy and simplified depiction of airlines' ambitions, the varying effectiveness of identified retailing approaches and associated prerequisites warrant a more differentiated discussion. This paper should help airline managers and scholars understand and further develop airline retailing and pathways towards customercentric airline retailing implementation.

\section{References}

Adaval, R., and K.B. Monroe. 2002. Automatic construction and use of contextual information for product and price evaluations. Journal of Consumer Research 28 (4): 572-588.

Albers, S., J. Daft, S. Stabenow, and V. Rundshagen. 2020. The longhaul low-cost airline business model: A disruptive innovation perspective. Journal of Air Transport Management 89: 101878.
Albers, S., and V. Rundshagen. 2020. European airlines' strategic responses to the COVID-19 pandemic (January-May, 2020). Journal of Air Transport Management 87: 101863.

Alderighi, M., A.A. Gaggero, and C.A. Piga. 2015. The effect of codeshare agreements on the temporal profile of airline fares. Transportation Research Part A: Policy and Practice 79: 42-54.

Amadeus IT Group. 2014. Thinking like a retailer-Airline merchandising. Frost \& Sullivan Report, pp. 1-21.

Angwin, J., and D. Mattioli. 2012. Coming soon: Toilet paper priced like airline tickets. http://online.wsj.com/article/SB10000872 $396390444914904577617333130724846 . h t m l$. Accessed 15 Nov 2020.

Aslani, S., M. Modarres, and S. Sibdari. 2014. On the fairness of airlines' ticket pricing as a result of revenue management techniques. Journal of Air Transport Management 40: 56-64.

Aydin, G., and S. Ziya. 2009. Personalized dynamic pricing of limited inventories. Operations Research 57 (6): 1523-1531.

Bilotkach, V. 2010. Reputation, search cost, and airfares. Journal of Air Transport Management 16 (5): 251-257.

Boyd, E.A. 2007. The future of pricing. New York: Wiley.

Boynton, C. 2012. The ancillary jungle. Air Transport World 49 (12): $45-46$

Budd, L., and T. Vorley. 2013. Airlines, apps, and business travel: A critical examination. Research in Transportation Business \& Management 9: 41-49.

Chen, Q., S. Jasin, and I. Duenyas. 2016b. Real-time dynamic pricing with minimal and flexible price adjustment. Management Science 62 (8): 2437-2455.

Chen, L., A. Mislove, and C. Wilson. 2016a. An empirical analysis of algorithmic pricing on Amazon marketplace. In Proceedings of the 25th International Conference on World Wide Web (pp. 1339-1349).

Chung, J.Y., and J.F. Petrick. 2012. Price fairness of airline ancillary fees: An attributional approach. Journal of Travel Research 52 (2): $168-181$

Clark, R., and N. Vincent. 2012. Capacity-contingent pricing and competition in the airline industry. Journal of Air Transport Management 24: 7-11.

Daft, J., and S. Albers. 2013. A conceptual framework for measuring airline business model. Journal of Air Transport Management 28: 47-54.

Daft, J., and M. Viehmann. 2019. The corner stones to develop a Dynamic Offer Management in the Airline Industry. Presented at AGIFORS Revenue Management Study Group Meeting, Panama.

Fageda, X., P. Suau-Sanchez, and K.J. Mason. 2015. The evolving low-cost business model: Network implications of fare bundling and connecting flights in Europe. Journal of Air Transport Management 42: 289-296.

Ferguson, M. 2014. Analysis: Airlines eye Amazon-style retail experience. Airline Business 30 (2): 58-63.

Fiig, T., U. Cholak, M. Gauchet, and B. Cany. 2015. What is the role of distribution in revenue management-Past and future. Journal of Revenue and Pricing Management 14 (2): 127-133.

Fiig, T., O. Goyons, R. Adelving, and B. Smith. 2016. Dynamic pricing-The next revolution in RM? Journal of Revenue and Pricing Management 15 (5): 360-379.

Flottau, J., C. Buyck, and B. Sumers. 2015. Airlines pledge to follow Lufthansa's move against GDS costs. Aviation Week \& Space Technology 15: 5-8.

Franke, N., P. Keinz, and C.J. Steger. 2009. Testing the value of customization: When do customers really prefer products tailored to their preferences? Journal of Marketing 73 (5): 103-121.

Franko, I. 2021. 2021 Airline digital trends report. Diggintravel. 
Golrezaei, N., H. Nazerzadeh, and P. Rusmevichientong. 2014. Realtime optimization of personalized assortments. Management Science 60 (6): 1532-1551.

Granados, N., R.J. Kauffman, H. Lai, and H. Lin. 2012. À La Carte pricing and price elasticity of demand in air travel. Decision Support Systems 53 (2): 381-394.

Grant, R. 2010. Contemporary strategy analysis, 7th ed. Hoboken, NJ: Wiley.

Hannak, A., G. Soeller, D. Lazer, A. Mislove, and C. Wilson. 2014. Measuring price discrimination and steering on E-commerce Web Sites. Proceedings of the 2014 Conference on Internet Measurement Conference-IMC' 14.

Hildebrand, C., G. Häubl, and A. Herrmann. 2014. Product customization via starting solutions. Journal of Marketing Research 51 (6): 707-725.

Homburg, C., D. Totzek, and M. Krämer. 2014. How price complexity takes its toll: The neglected role of a simplicity bias and fairness in price evaluations. Journal of Business Research 67 (6): 1114-1122.

Hoyles, Y. 2015. IATA Simplifying the Business. New Distribution Capability (NDC). Facilitating Air Retailing. http://www.iata. org/whatwedo/airline-distribution/ndc/Documents/ndc-strategypaper.pdf. Accessed 10 Jan 2018

Isler, K., and E. D'Souza. 2009. GDS capabilities, OD control and dynamic pricing. Journal of Revenue and Pricing Management $8(2 / 3): 255-266$.

Jainchill, J., and R. Silk. 2019. Will the subscription model fly for car rentals and airlines? Travel Weekly 78 (24): 8-8.

Jenner, G. 2017. Special report. Airline Business, pp. 1-7.

Koo, B., B. Mantin, and P. O'Connor. 2011. Online distribution of airline tickets: Should airlines adopt a single or a multi-channel approach? Tourism Management 32 (1): 69-74.

Malighetti, P., S. Paleari, and R. Redondi. 2009. Pricing strategies of low-cost airlines: The Ryanair case study. Journal of Air Transport Management 15 (4): 195-203.

Mantin, B., and B. Koo. 2010. Weekend effect in airfare pricing. Journal of Air Transport Management 16: 48-50.

McDonald, M. 2015. Bookings battle. Air Transport World 52 (10): 34-36.

O’Connell, J.F., and D. Warnock-Smith. 2013. An investigation into traveler preferences and acceptance levels of airline ancillary revenues. Journal of Air Transport Management 33: 12-21.

Odegaard, F., and J.G. Wilson. 2016. Dynamic pricing of primary products and ancillary services. European Journal of Operational Research 251 (2): 586-599.

Rauch, J., K. Isler, and S. Poelt. 2018. Disentangling capacity control from price optimization. Journal of Revenue and Pricing Management 17: 48-62.
Scotti, D., M. Dresner, and G. Martini. 2016. Baggage fees, operational performance and customer satisfaction in the US air transport industry. Journal of Air Transport Management 55: 139-146.

Stremersch, S., and G.J. Tellis. 2002. Strategic bundling of products and prices: A new synthesis for marketing. Journal of Marketing 66 (1): 55-72.

Tarry, C. 2010. Low-cost commodity. Airline Business 26: 28-30.

Tretheway, M.W., and K. Markhvida. 2014. The aviation value chain: Economic returns and policy issues. Journal of Air Transport Management 41: 3-16.

U.S. Department of Commerce. 2020. Estimated Quarterly U.S. Retail Sales (Adjusted): Total and E-commerce. Timeseries data. https:// www.census.gov/retail/index.html. U.S. Census Bureau. Accessed 10 Dec 2020.

van Ryzin, G., and K. Talluri. 2005. An introduction to revenue management. In Tutorials in operations research, 142-192. Hanover: INFORMS.

Vinod, B. 2007. The continuing evolution: Customer-centric revenue management. Journal of Revenue and Pricing Management 7 (1): 27-39.

Vinod, B. 2010. The complexities and challenges of the airline fare management process and alignment with revenue management. Journal of Revenue and Pricing Management 9 (1-2): 137-151.

Vinod, B., and K. Moore. 2009. Promoting branded fare families and ancillary services: Merchandising and its impacts on the travel value chain. Journal of Revenue and Pricing Management 8 (2-3): 174-186.

Walker, K. 2012. The unbundling dichotomy. Air Transport World 49 (9): 7.

Wang, K. 2020. DOG Mixed bundling with the Markov Chain Choice model. Presented at PODS Meeting, Seattle.

Westermann, D. 2013. The potential impact of IATA's new New Distribution Capability (NDC) on revenue management and pricing. Journal of Revenue and Pricing Management 12 (6): 565-568.

Wittmann, M. D., and P. P. Belobaba. 2016. Customized Offers in Airline Revenue Management. 56th AGIFORS Symposium Proceedings, pp. 1-40.

Publisher's Note Springer Nature remains neutral with regard to jurisdictional claims in published maps and institutional affiliations. 